\title{
Effluent Discharges from Two Outfalls on a Sloping Beach
}

\author{
Anton Purnama \\ Department of Mathematics and Statistics, College of Science, Sultan Qaboos University, Muscat, \\ Sultanate of Oman \\ Email: antonp@squ.edu.om
}

Received 15 August 2014; revised 10 September 2014; accepted 7 October 2014

Copyright (C) 2014 by author and Scientific Research Publishing Inc.

This work is licensed under the Creative Commons Attribution International License (CC BY).

http://creativecommons.org/licenses/by/4.0/

c) (i) Open Access

\begin{abstract}
A marine outfall is a long pipeline that continuously discharges large amounts of effluent streams into the sea. As the number of marine outfalls along the coastal areas is growing, a far field mathematical model with two point sources on a sloping beach is used to assess the coastal water quality following discharges from two outfalls. Asymptotic approximation will be made to the concentration at the beach to measure how well the effluent plumes are mixed and diluted in the coastal waters. The result found agrees with the engineering practice of installing a two-port diffuser at the end of a single outfall to minimize its potential environment impacts.
\end{abstract}

\section{Keywords}

Advection Diffusion Equation, Far Field Model, Two-Port Diffuser, Two Point Sources

\section{Introduction}

Most coastal industrial installations and plants, such as municipal sewage treatment plants [1] [2], power generation stations [3], and seawater desalination plants [4]-[8], dispose of their wastewater effluents through long outfall pipes that stretch far into the ocean. For a modern plant, a multiport diffuser would also be installed at the pipe-end to rapidly dilute the effluent stream. Because of relatively shallow coastal waters, it is observed that the elongated effluent plumes are spreading towards the shoreline and may cause a concentration build-up [9]-[11]. Due to the uncertainty in sea conditions, a clear understanding of the mixing processes of effluent plumes is not yet known, and the use of mathematical models has been a key strategy for the basis of sound engineering design and for assessing the potential environmental impacts of marine outfall effluent discharges [2] [3] [5]-[8].

When many marine outfalls are discharging effluents to shallow coastal waters, the adverse long-term impacts are strongly inter-dependent, and compounded from neighbouring outfalls. The interactions of two or more 
effluent plumes are expected as many outfalls often tend to be closely clustered together along the coastal areas. Newly-constructed coastal plants may need to build two outfalls as a contingency plan for a future increase in the plant's production capacity [6]. For two outfalls discharging a given integrated total effluent stream, the waste load can be allocated optimally between them to minimise the impact [12] [13].

As coastal industrial plants are built predominantly on the sloping sandy beaches, a mathematical model using a two-dimensional advection diffusion equation with two point sources is presented. The solution is plotted to graphically study the merging of two effluent plumes from two outfalls. While the far field modelling in this paper involves drastic simplifications, key physical mixing and dispersion processes are represented, and thus the analytical solution remains useful in providing a qualitative understanding and in suggesting general behaviour of the marine outfall effluent discharge plumes in coastal environment [9] [11] [12].

\section{Mathematical Analysis}

The beach is considered to be straight and the sea wide, and the outfall's effluent plume is assumed to be vertically well-mixed over the water depth. The coastal (drift) current is assumed to be steady with a speed $U$ and remains in the $x$-direction parallel to the beach at all times. The dispersion mechanisms are represented by eddy diffusivities, and diffusion in the $x$-direction is neglected, as the effluent plumes in steady currents become very elongated in the $x$-direction. The variations in the $y$-direction of $U$ and coefficient of dispersivity $D$ are assumed as the power functions only of water depth $h$, and for application, we take $U$ to be proportional to $h_{0}^{1 / 2}$ and $D$ to $h_{0}^{3 / 2}$, where $h_{0}$ is an arbitrary reference water depth. These scalings are appropriate for a turbulent shallow water flow over a smooth bed [9]-[11] [14]. For simplicity, other complexities such as tidal motions, density and temperature are ignored.

As illustrated in Figure 1, we represent the old outfall as a point source at the position $\left(x_{0}=0, y_{0}=\alpha h_{0}\right)$ discharging an effluent stream at a constant rate $Q_{0}$, where $\alpha$ is the source length. Similarly, the new outfall as a point source at $\left(x_{1}=-\ell h_{0}, y_{1}=(\alpha+\varepsilon) h_{0}\right)$ discharges at a rate $Q_{1}$, where $\varepsilon$ is the outfall's (offshore) and $\ell$ (along the shore) separation distances. Without loss of generality, we also assume that if these two outfalls are operated by one plant discharging, then a combined effluent total rate $Q=Q_{0}+Q_{1}$.

As the water depth is gradually decreasing towards the beach at $y=0$, on a uniformly sloping beach with slope $m$, we formulate $h(y)=m y$. Following [9] [11] and applying a linear superposition, the two-dimensional advection-diffusion equation for the far field plume concentration $c(x, y)$ from the two point sources is given by

$$
\frac{\partial}{\partial x}(h U c)-\frac{\partial}{\partial y}\left(h D \frac{\partial c}{\partial y}\right)=Q_{0} \delta\left(x+x_{0}\right) \delta\left(y-y_{0}\right)+Q_{1} \delta\left(x+x_{1}\right) \delta\left(y-y_{1}\right)
$$

with boundary condition $h D \partial c / \partial y=0$ at the beach $y=0$, and the effluent concentration is assumed to be ultimately dissolved far into the sea, $c \rightarrow 0$ as $y \rightarrow \infty$. $\delta$ is the Dirac delta function. In terms of dimensionless quantities

$$
y=y_{*} h_{0}, \quad x=x_{*} h_{0}, \quad c(x, y)=c_{*}\left(x_{*}, y_{*}\right) Q / h_{0}^{2} U_{0}, \quad q_{0}=Q_{0} / Q \text { and } q_{1}=Q_{1} / Q,
$$

where $Q$ denotes a reference discharge rate which usually adopts the value of the original discharge rate of the old outfall. By setting

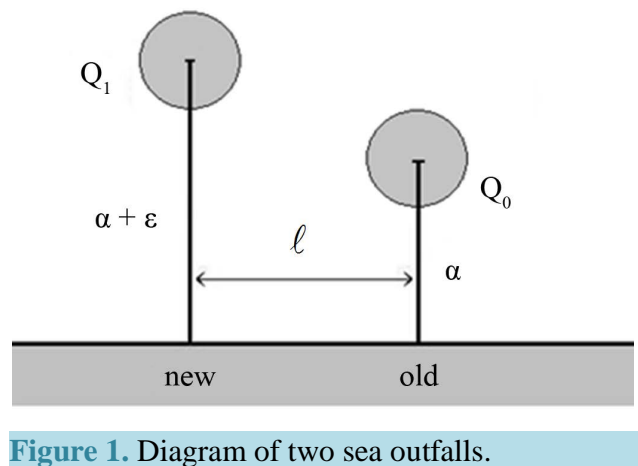

Figure 1. Diagram of two sea outfalls. 


$$
\lambda=h_{0} U_{0} / D_{0}, \quad U=U_{0} y_{*}^{1 / 2} \text { and } D=D_{0} y_{*}^{3 / 2},
$$

the analytical solution of Equation (1) is given by

$$
\begin{aligned}
c_{*}\left(x_{*}, y_{*}\right)= & q_{0} \frac{\lambda}{m x_{*}}\left(\frac{1}{\alpha y_{*}}\right)^{3 / 4} \exp \left\{-\frac{\lambda\left(y_{*}+\alpha\right)}{x_{*}}\right\} I_{3 / 2}\left(\frac{2 \lambda \sqrt{\alpha y_{*}}}{x_{*}}\right) \\
& +q_{1} \frac{\lambda}{m\left(x_{*}+\ell\right)}\left(\frac{1}{[\alpha+\varepsilon] y_{*}}\right)^{3 / 4} \exp \left\{-\frac{\lambda\left(y_{*}+\alpha+\varepsilon\right)}{x_{*}+\ell}\right\} I_{3 / 2}\left(\frac{2 \lambda \sqrt{[\alpha+\varepsilon] y_{*}}}{x_{*}+\ell}\right),
\end{aligned}
$$

where $I_{3 / 2}$ is a modified Bessel function [15] [16]. The model parameter $\lambda$ represents the effluent plume elongation in the $x$-direction [9]-[11]. In coastal waters, larger values of $\lambda$ are mostly due to a stronger current $U_{0}$ with less dispersivity $D_{0}$. For the quantitative illustration of the solutions, the values of $m=0.02$ and $\lambda=5 / 2$ will be used in all plots. The other parameters are related to the position of the point sources: $\alpha$ the single point source length, and $\varepsilon$ and $\ell$ the point source's separation distances.

As a higher build-up in concentration is more likely found at the shallow water close to the beach [7] [8] [10] [14], the appropriate measure for assessing the impact of marine effluent discharges from sea outfalls would be the concentration values at the beach. In the limit as $y_{*} \rightarrow 0$ and replacing $I_{3 / 2}$ in Equation (2) by its asymptotic form [16], we obtain the compounded concentration at the beach

$$
c_{*}\left(x_{*}, 0\right) \approx \frac{4}{3 m \sqrt{\pi}} q_{0}\left(\frac{\lambda}{x_{*}}\right)^{5 / 2} \exp \left(-\frac{\lambda \alpha}{x_{*}}\right)+\frac{4}{3 m \sqrt{\pi}} q_{1}\left(\frac{\lambda}{x_{*}+\ell}\right)^{5 / 2} \exp \left\{-\frac{\lambda(\alpha+\varepsilon)}{x_{*}+\ell}\right\} .
$$

It is easy to see for effluent discharges from a single point source at $\left(x_{0}=0, y_{0}=\alpha h_{0}\right)$ and since $q_{0}=1$ (and $q_{1}=0$ ), the concentration at the beach reduces to

$$
c_{0^{*}}\left(x_{*}, 0\right) \approx \frac{4}{3 m \sqrt{\pi}}\left(\frac{\lambda}{x_{*}}\right)^{5 / 2} \exp \left(-\frac{\lambda \alpha}{x_{*}}\right) .
$$

The concentration at the beach for a point source length $\alpha=3$ and $\alpha=4$ is plotted in Figure 2. By differentiating, the concentration has a maximum value of $c_{0 m} \approx 0.61 / m \alpha^{5 / 2}$, which occurs at the position $x_{*_{m}}=2 \lambda \alpha / 5$. This maximum value is inversely proportional to the point source length $\alpha$ [9] [10]. A value of 1.96 is obtained for $\alpha=3$, and this maximum value is reduced by more than $50 \%$ to 0.95 when the length is extended to $\alpha=4$. This result agrees with the standard practice of building a longer sea outfall in order to minimize its potential environmental impact in the coastal waters [1] [2].

\section{Two Independent Outfalls}

Apart from the effluent discharge rates, the compounded impact of the new outfall is governed by the outfall's separation distances $\varepsilon$ and $\ell$, and in particular, if the value of $\ell$ is large (e.g. $\ell>5 x_{*_{m}}$ ), the two outfalls are well separated, and thus it is expected that the contribution of the new outfall located at $\left(x_{1}=-\ell h_{0}\right.$, $\left.y_{1}=(\alpha+\varepsilon) h_{0}\right)$ is negligible [9].

We first consider the case where the two outfalls are operated independently by two coastal plants, i.e., when $q_{0}+q_{1} \neq 1$ and when both separation distances $\ell>0$ and $\varepsilon>0$. The concentration contour plots of Equation (2), the solution for two point sources when $\alpha=3$ and $\varepsilon=2$, is shown in Figure 3, which illustrates the merging of plumes from the two point sources for two values of the separation distance $\ell=3$ with $q_{0}=1$ and $q_{1}=0.5$, and $\ell=8$ with $q_{0}=0.5$ and $q_{1}=1$, where two separate plumes are clearly shown.

Since the value $\lambda=5 / 2$ is used in the plot, $x_{*_{m}}=2 \lambda \alpha / 5=\alpha=3$ and the top part of Figure 3 represents a situation where two outfalls are relatively close to each other at a small distance apart, $\ell=3=x_{*_{m}}$, and the new point source is discharging with a rate $q_{1}=0.5$, half of the old point source at $\left(x_{0}=0, y_{0}=\alpha h_{0}\right)$. The bottom part of Figure 3 represents two outfalls at a slightly longer distance apart, $\ell=8 \approx 2.67 x_{*_{m}}$, where the new point source is discharging with a rate $q_{1}=1$, double that of the old point source.

Next, the compounded concentration at the beach for two point sources as given by Equation (3) can be simplified to 


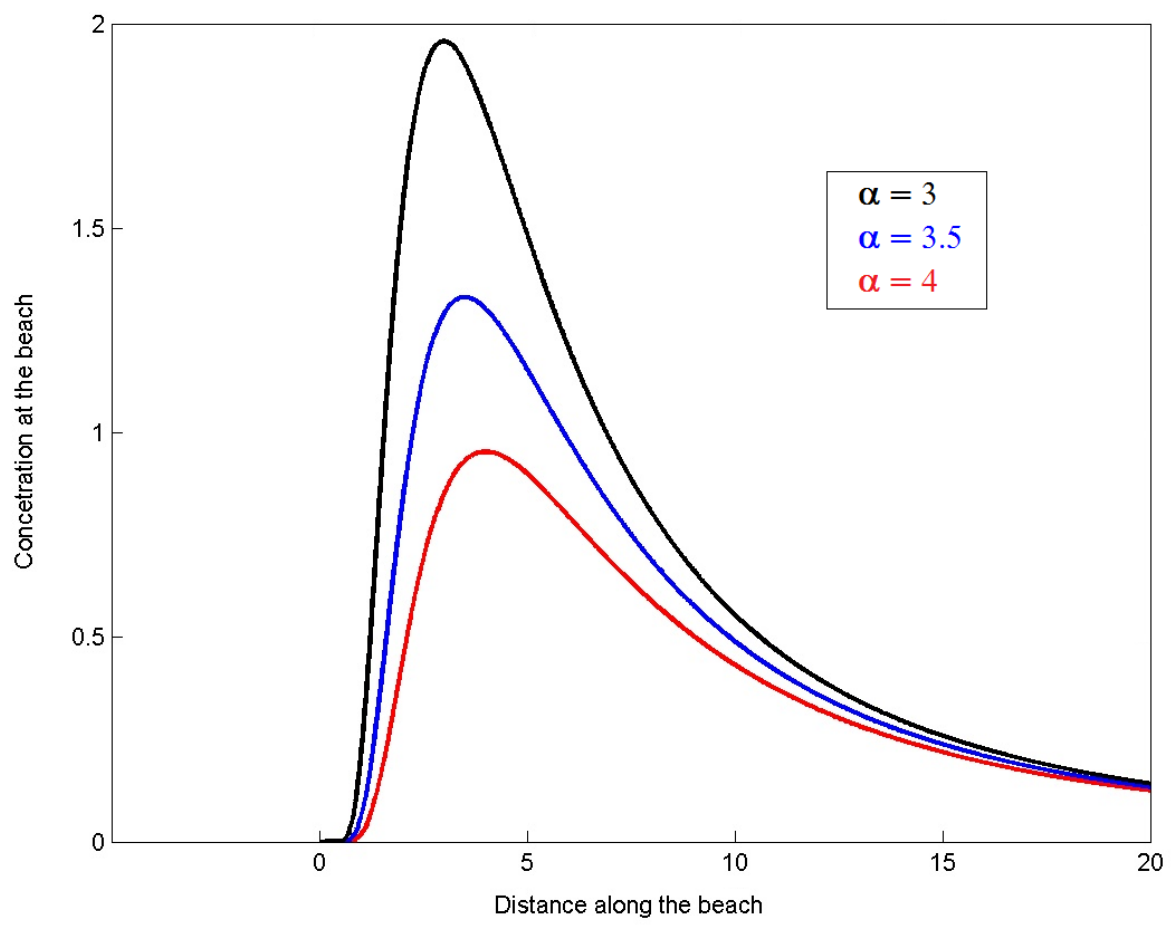

Figure 2. The concentration at the beach for a single point source.

$$
c_{*}\left(x_{*}, 0\right) \approx c_{0^{*}}\left(x_{*}, 0\right)\left[q_{0}+q_{1}\left(\frac{x_{*}}{x_{*}+\ell}\right)^{5 / 2} \exp \left\{-\frac{\lambda}{x_{*}}\left(\frac{\varepsilon x_{*}-\alpha \ell}{x_{*}+\ell}\right)\right\}\right] .
$$

Figure 4 shows the concentration at the beach for the two cases illustrated in Figure 3, where two separated plumes are depicted as two distinctive peaks. For comparison, the concentration for the single point source with $q_{0}=1$ is also shown in Figure 4 by the dotted line. It is worth noting that for $x_{*}>0$, the presence of the new outfall does not change the location of the maximum concentration at the beach [11].

Substituting $x_{*_{m}}=2 \lambda \alpha / 5$ in Equation (4), the maximum value of concentration at the beach for two point sources is approximated as

$$
c_{1 m} \approx c_{0 m}\left[q_{0}+q_{1} f(z)\right]
$$

where $z=\ell / x_{*_{m}}=(5 / 2 \lambda)(\ell / \alpha)$ and

$$
f(z)=(1+z)^{-5 / 2} \exp \left(-\frac{5}{2}\left\{\frac{\varepsilon / \alpha-z}{1+z}\right\}\right) .
$$

By differentiating, $f(z)$ has a maximum value of $f_{m}=(1+\varepsilon / \alpha)^{-5 / 2}$, which occurs at $z_{m}=\varepsilon / \alpha$, and therefore

$$
c_{1 m} \leq c_{0 m}\left[q_{0}+q_{1}\left(1+\frac{\varepsilon}{\alpha}\right)^{-5 / 2}\right] .
$$

Note that for a given value of $z_{m}=\varepsilon / \alpha$, the value of $\ell / \alpha$ can be determined by $\ell / \alpha=(2 \lambda / 5)(\varepsilon / \alpha)$.

As shown in Figure 5, the largest maximum value of compounded concentration at the beach for two point sources is always greater than that of the concentration at the beach for a single point source. The contribution of the new outfall is much greater for $\varepsilon / \alpha<1$. For example, if the new point source length is double that of the old point source length, i.e. $\varepsilon / \alpha=1$ (and $\ell / \alpha=\varepsilon / \alpha$ for $\lambda=5 / 2$ ), then from Equation (5), the maximum value of the concentration at the beach is $c_{1 m} \approx q_{0} c_{0 m}\left[1+0.18 q_{1} / q_{0}\right]$. If both point sources are discharging at 

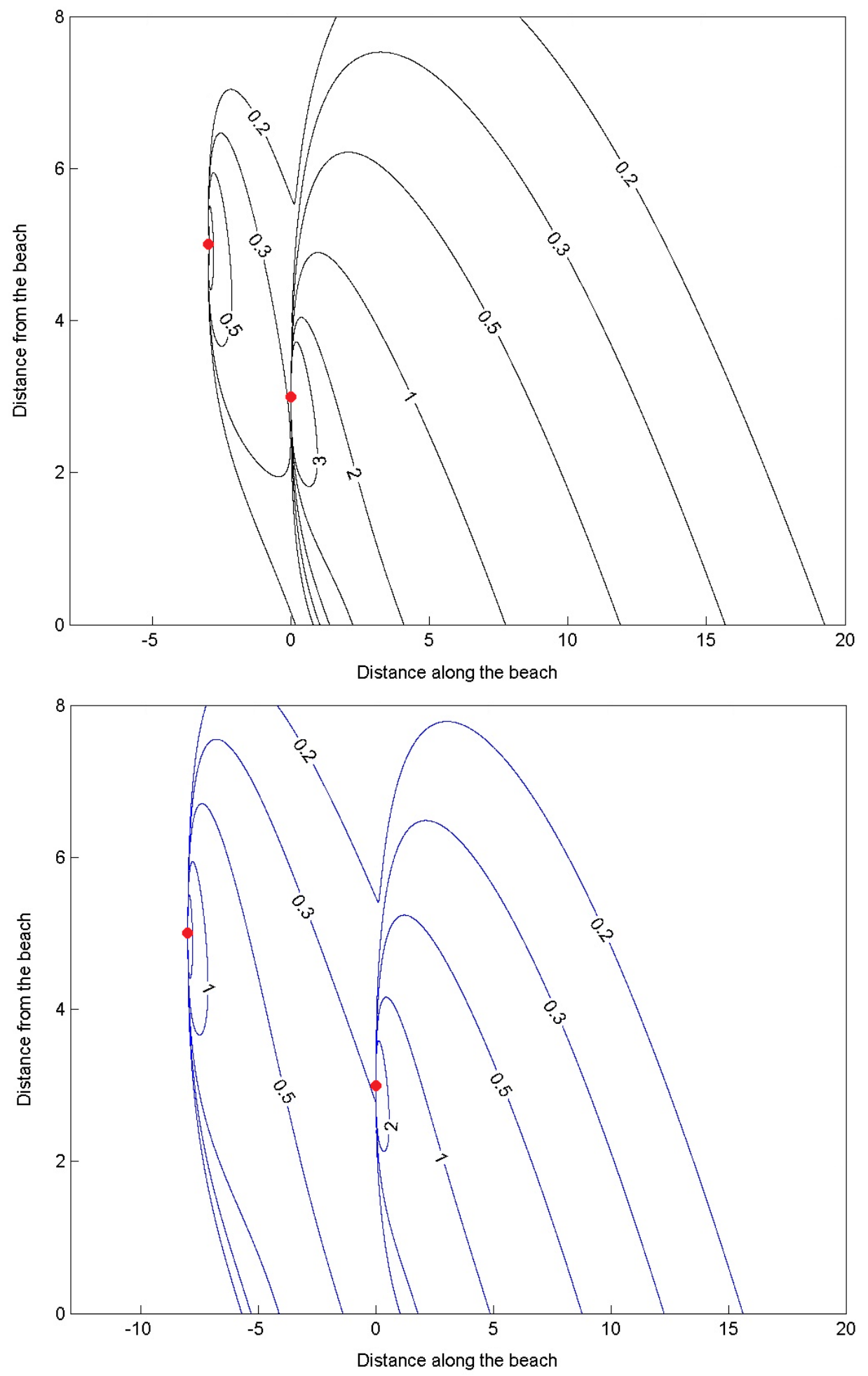

Figure 3. Merging contour of two point sources plumes when $\alpha=3$ and $\varepsilon=2$.

equal rates, i.e. $q_{1} / q_{0}=1$, then the maximum value of $c_{1 m}$ is about $18 \%$ higher than $q_{0} c_{0 m}$, the maximum value of the single point source. However, if $q_{1} / q_{0}=1.5$, the maximum value of $c_{1 m}$ is increased to about $27 \%$ higher than $q_{0} c_{0 m}$. 


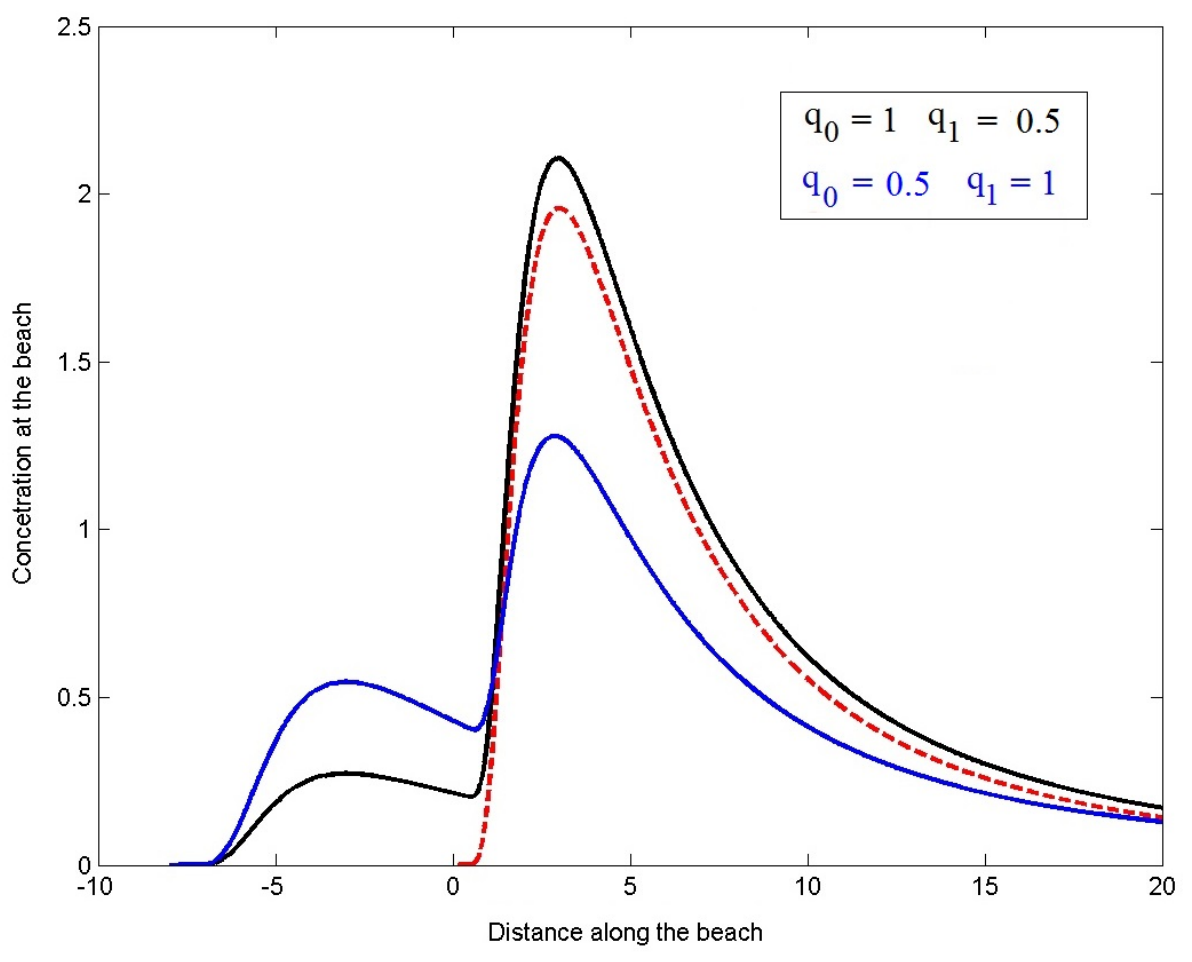

Figure 4. Compounded concentration at the beach for two point sources.

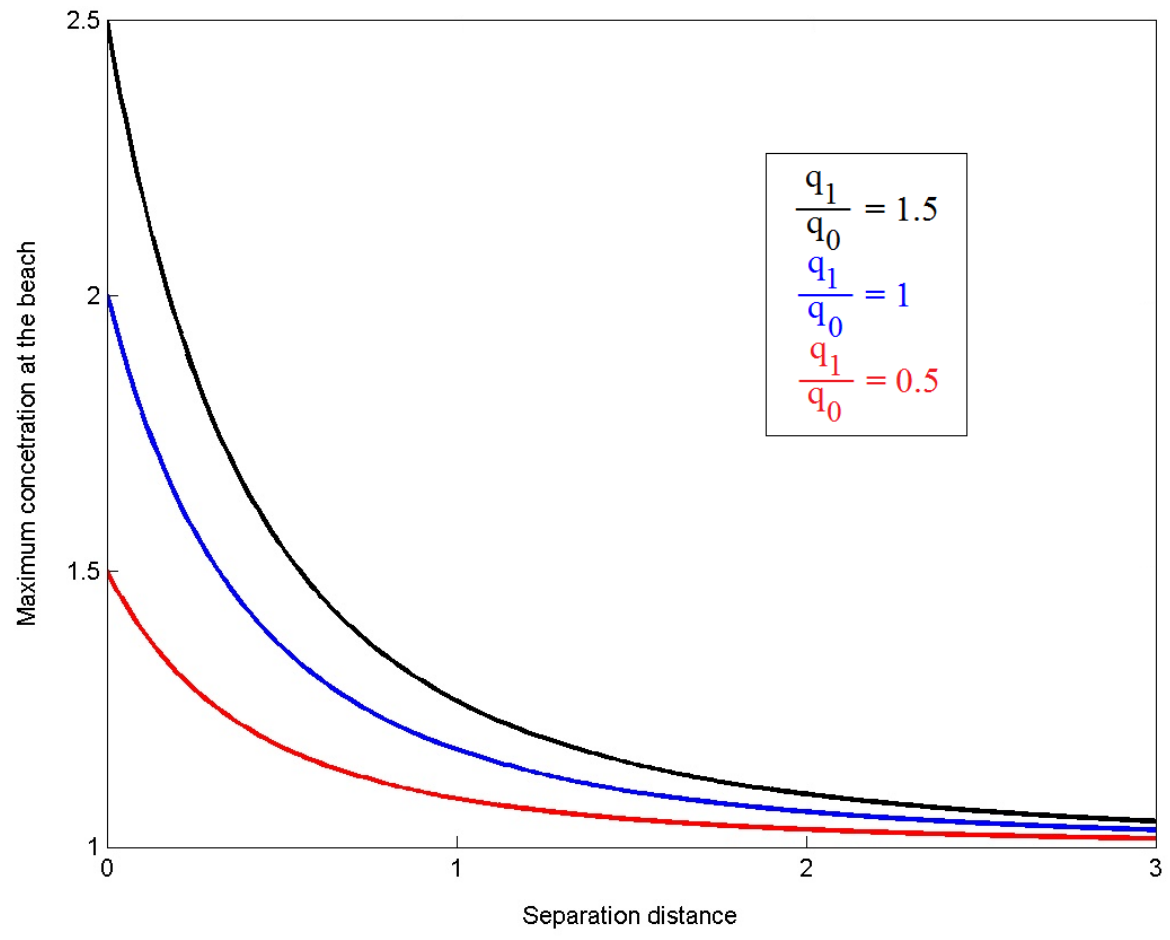

Figure 5. Maximum value of $c_{1 m} / q_{0} c_{0 m}$.

\section{Single Outfall with Two Ports}

Modifying the rates of discharge can be achieved through a relatively less expensive method than extending the 
outfall lengths. For the case where two outfalls is operated by one plant, i.e. when $q_{0}+q_{1}=1$, the effluent discharge allocation can be arranged between these two outfalls [12]. Binomial expansion of Equation (5) for $\varepsilon / \alpha<1$, gives

$$
c_{1 m} \approx c_{0 m}\left[q_{0}+q_{1}\left(1+\frac{\varepsilon}{\alpha}\right)^{-5 / 2}\right] \approx c_{0 m}\left[1-q_{1}\left(\frac{5 \varepsilon}{2 \alpha}\right)\left\{1-\frac{7 \varepsilon}{4 \alpha}+\cdots\right\}\right] .
$$

That is, the maximum value of $c_{1 m}$ is smaller than that of the single point source value $c_{0 m}$. This result agrees with the previous finding [12] [13], that if two outfalls are discharging a given integrated total effluent stream, the waste load can be allocated optimally between them to minimise the impact. However, economically it is cheaper to build an outfall and install a two-port diffuser at its pipe-end than build one more sea outfall.

To include the case of the modern engineering practice that installs two ports at the end of a marine outfall [5] [6], we also assume that both port separation distances $\varepsilon / \alpha$ and $\ell / \alpha$ are small, and thus the value of $f(z)$ can be approximated for $z \leq 0.05$ by $f_{0} \approx \exp (-5 \varepsilon / 2 \alpha)$.

For plotting the contours of the effluent plume, since the point sources are close to each other, and in the limit as $X_{*} \rightarrow 0$ and replacing $I_{3 / 2}$ in Equation (2) by its asymptotic form [16], we obtain

$$
c_{*}\left(x_{*}, y_{*}\right)=\frac{q_{0}}{m \alpha y_{*}} \sqrt{\frac{\lambda}{4 \pi x_{*}}} \exp \left\{-\frac{\lambda\left(\sqrt{y_{*}}-\sqrt{\alpha}\right)^{2}}{x_{*}}\right\}+\frac{q_{1}}{m(\alpha+\varepsilon) y_{*}} \sqrt{\frac{\lambda}{4 \pi\left(x_{*}+\ell\right)}} \exp \left\{-\frac{\lambda\left(\sqrt{y_{*}}-\sqrt{\alpha+\varepsilon}\right)^{2}}{x_{*}+\ell}\right\} .
$$

The contours of the solution for a single outfall with two ports are reproduced graphically in Figure 6 for $\alpha=3$ with $q_{0}=q_{1}=0.5$, when $z=0.05$, which is equivalent to the port separation distance $\ell / \alpha=0.05$ for $\lambda=5 / 2$. The effluent plumes from these two closely located point sources are immediately merged as they are released, and for $x_{*}>0$, and the combined plumes appears to be spreading as one. This supports the concept that a two-port diffuser will rapidly dilute effluent streams.

Finally, the maximum value of compounded concentration at the beach for two closely located point sources can be approximated to

$$
c_{1 m} \approx c_{0 m}\left[q_{0}+q_{1} \exp \left(-\frac{5 \varepsilon}{2 \alpha}\right)\right] \approx c_{0 m}\left[1-q_{1}\left(\frac{5 \varepsilon}{2 \alpha}\right)\left\{1-\frac{5 \varepsilon}{4 \alpha}+\cdots\right\}\right] .
$$

Again, the maximum value of $c_{1 m}$ is smaller than that of the single point source value $c_{0 m}$. From Figure 7, we noted that as the value of $q_{1}$ increases and the port separation distance $\varepsilon / \alpha$ gets longer, the maximum value becomes smaller than $c_{0 m}$. For example, if $\varepsilon / \alpha=0.1$ and both ports are discharging at equal rates, i.e. $q_{1}=q_{0}=0.5$, then the maximum value of $c_{1 m}$ is about $10 \%$ less than $c_{0 m}$. This result agrees with the modern engineering practice that installing a two-port diffuser at the end of a marine outfall will improve the mixing and dilution of effluent discharge plumes in coastal waters [5] [6] [12].

\section{Conclusions}

The solutions for an advection diffusion equation with two point sources are applied to study the interaction and merging of effluent discharge plumes from two outfalls on a sloping beach. As a measure for assessing the impact in the coastal environment, the maximum compounded concentration at the beach is formulated. If the two outfalls are independently operated, then the maximum value of the concentration at the beach can be minimized as long as the new outfall length is more than double the old outfall length, and discharging at a rate smaller than the old outfall.

If two outfalls are operated by one plant, then the integrated total effluent load can be shared between them, and it is found that the maximum value of the concentration at the beach is smaller than that of the single outfall. A similar result is also obtained for a single outfall where a two-port diffuser is installed at the end outfall pipe. However, implementation issues related to the control of discharge rates, reliability and cost effectiveness of the marine outfall are not addressed.

The mathematical formulation presented can be extended to the case of multiple outfalls discharging on a coastal area, and in particular, the result for effluent discharges from multiport diffusers has been reported in [11]. 

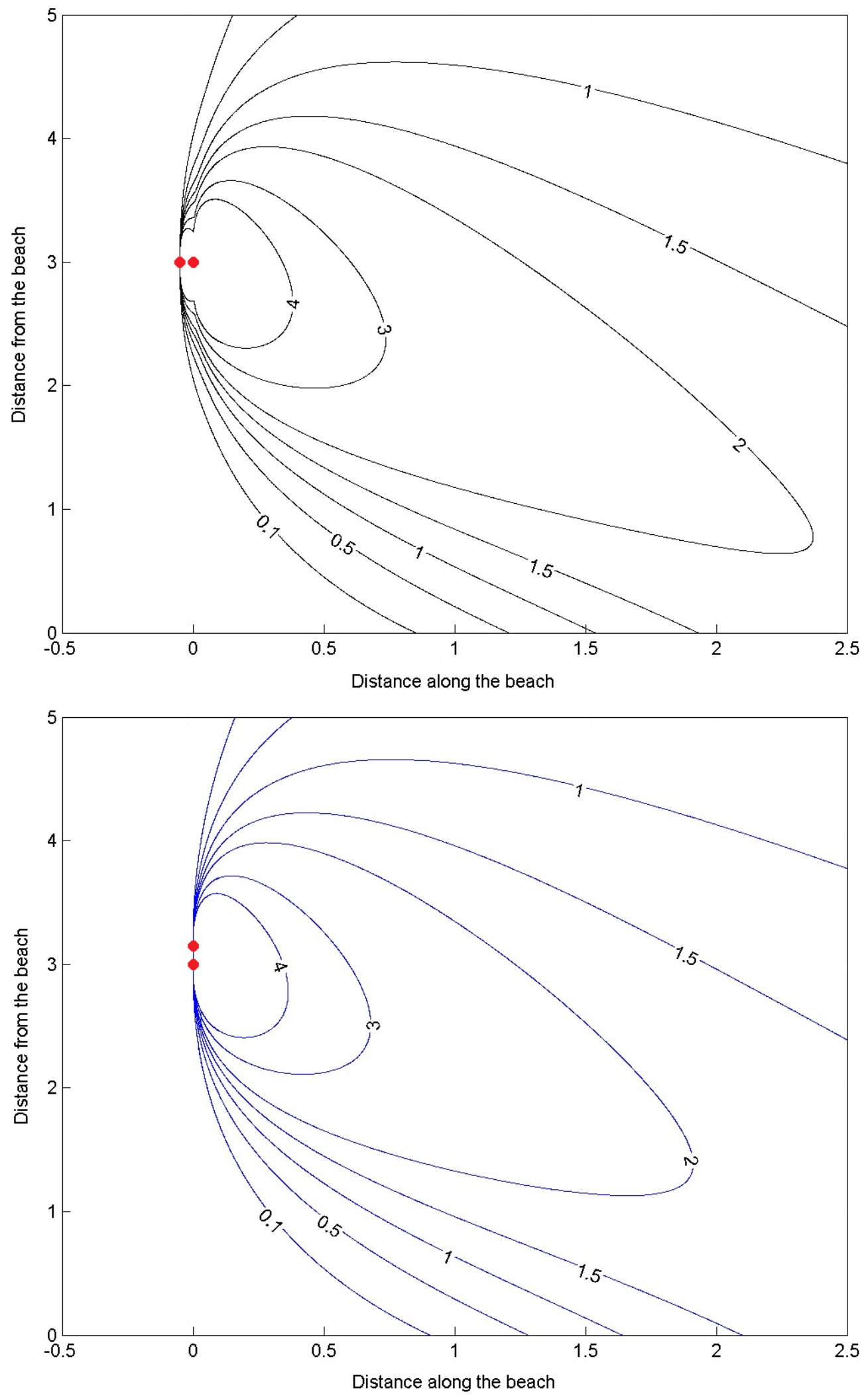

Figure 6. Combined plumes of two closely located point sources for $\alpha=3$ with $q_{0}=q_{1}=0.5$. 


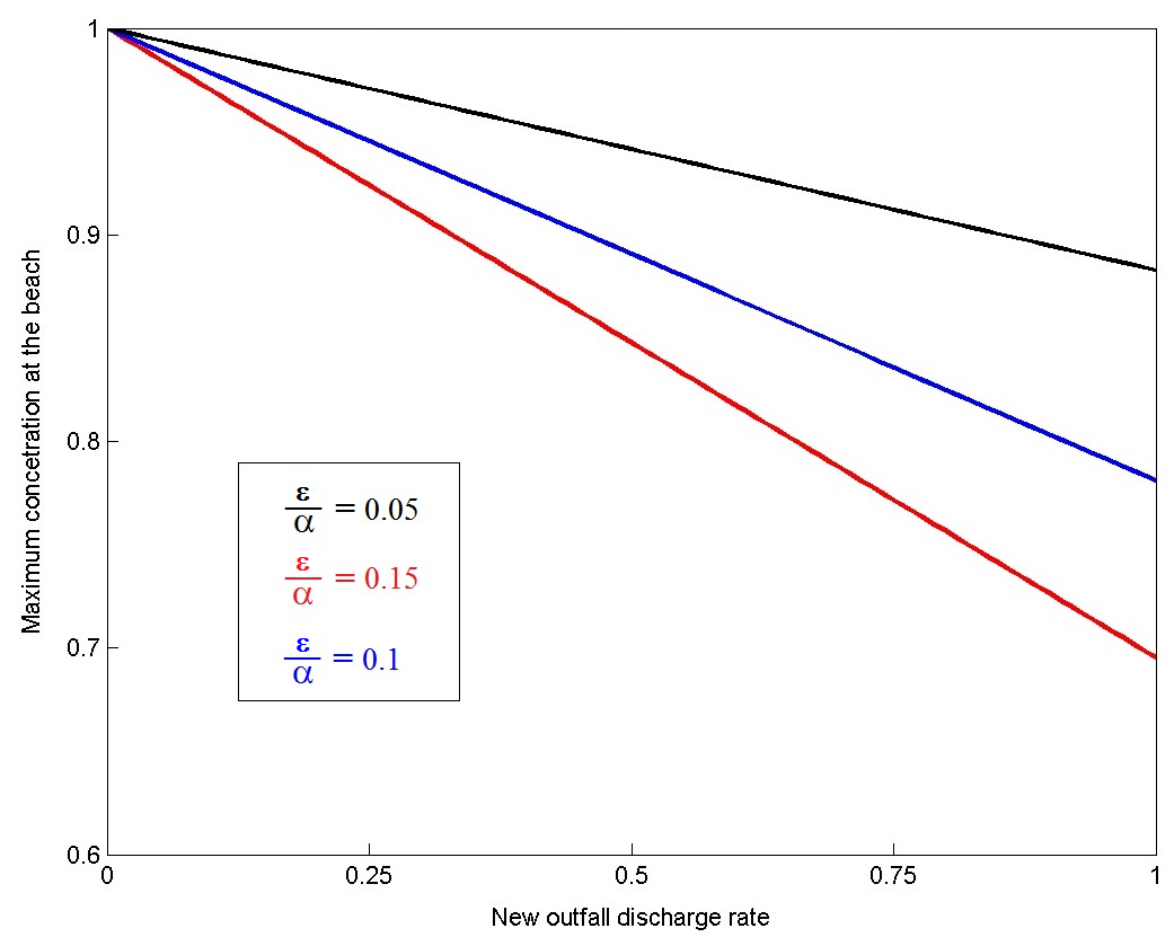

Figure 7. Maximum value of $c_{1 m} / c_{0 m}$.

\section{Acknowledgements}

The author is grateful to Sultan Qaboos University for an Internal Grant IG/SCI/DOMS/14/01 which provided financial support for this work.

\section{References}

[1] Institution of Civil Engineers (2001) Long Sea Outfalls. Thomas Telford Ltd., London.

[2] Signell, R.P.,Jenter, H.L. and Blumberg A.F. (2000)Predicting the Physical Effects of Relocating Boston's Sewage Outfall. Estuarine, Coastal and Shelf Sciences, 50, 59-71. http://dx.doi.org/10.1006/ecss.1999.0532

[3] Macqueen, J.F. and Preston, R.W. (1983) Cooling Water Discharges into a Sea with a Sloping Bed. Water Research, 17, 389-395. http://dx.doi.org/10.1016/0043-1354(83)90134-3

[4] Lattemann, S. and Hopner, T. (2008) Environmental Impact and Impact Assessment of Seawater Desalination. Desalination, 220, 1-15. http://dx.doi.org/10.1016/j.desal.2007.03.009

[5] Bleninger, T. and Jirka, G.H. (2008) Modelling and Environmentally Sound Management of Brine Discharges from Desalination Plants. Desalination, 221, 585-597. http://dx.doi.org/10.1016/j.desal.2007.02.059

[6] Purnama, A., Al-Barwani, H.H., Bleninger, T. and Doneker, R.L. (2011) CORMIX Simulations of Brine Discharges from Barka Plants, Oman. Desalination and Water Treatment, 32, 329-338. http://dx.doi.org/10.5004/dwt.2011.2718

[7] Roberts, D.A., Johnston, E.L. and Knott, N.A. (2010) Impacts of Desalination Plant Discharges on the Marine Environment: A Critical Review of Published Studies. Water Research, 44, 5117-5128. http://dx.doi.org/10.1016/j.watres.2010.04.036

[8] Palomar, P. and Losada, I.J. (2011) Impacts of Brine Discharge on the Marine Environment. Modelling as a Predictive Tool. In: Schorr, M., Ed., Desalination, Trends and Technologies, InTech Open Access Publisher, Rijeka, Croatia, 279-310.

[9] Al-Barwani, H.H. and Purnama, A. (2009) Analytical Solutions for Brine Discharge Plumes on a Sloping Beach. Desalination and Water Treatment, 11, 2-6. http://dx.doi.org/10.5004/dwt.2009.835

[10] Kay, A. (1987) The Effect of Cross-Stream Depth Variations upon Contaminant Dispersion in a Vertically Well-Mixed Current. Estuarine and Coastal Shelf Science, 24, 177-204. http://dx.doi.org/10.1016/0272-7714(87)90064-3 
[11] Purnama, A. (2012) Merging Effluent Discharge Plumes from Multiport Diffusers on a Sloping Beach. Applied Mathematics, 3, 24-29. http://dx.doi.org/10.4236/am.2012.31004

[12] Smith, R. and Purnama, A. (1999) Two Outfalls in an Estuary: Optimal Wasteload Allocation. Journal of Engineering Mathematics, 35, 273-283. http://dx.doi.org/10.1023/A:1004332007489

[13] Bikangaga, J.H. and Nassehi, V. (1995) Application of Computer Modeling Techniques to the Determination of Optimum Effluent Discharge Policies in Tidal Water Systems. Water Research, 29, 2367-2375. http://dx.doi.org/10.1016/0043-1354(95)00045-M

[14] Smith, R. (1976) Longitudinal Dispersion of Buoyant Contaminant in a Shallow Channel. Journal of Fluid Mechanics, 78, 677-688. http://dx.doi.org/10.1017/S0022112076002681

[15] Murphy, G.M. (1960) Ordinary Differential Equations and Their Solutions. D. Van Nostrand, London.

[16] Gradshteyn, I.S. and Ryzhik, I. (1980) Tables of Integrals, Series and Products. Academic Press, London. 
Scientific Research Publishing (SCIRP) is one of the largest Open Access journal publishers. It is currently publishing more than 200 open access, online, peer-reviewed journals covering a wide range of academic disciplines. SCIRP serves the worldwide academic communities and contributes to the progress and application of science with its publication.

Other selected journals from SCIRP are listed as below. Submit your manuscript to us via either submit@scirp.org or Online Submission Portal.
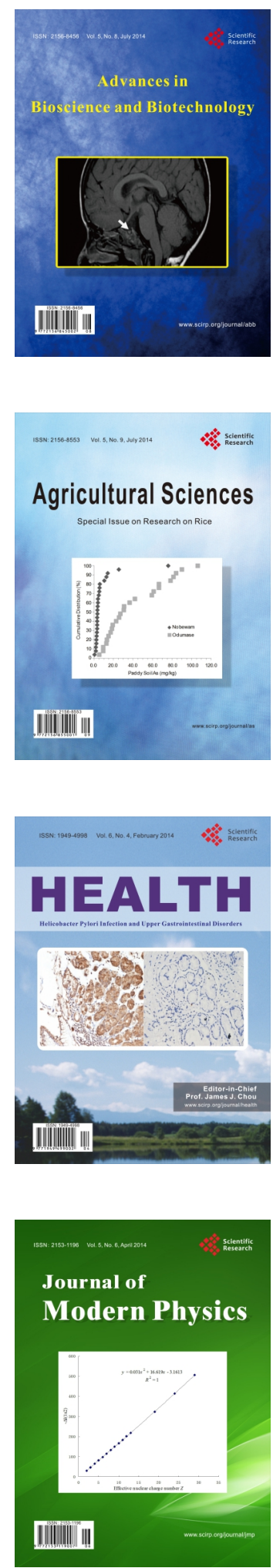
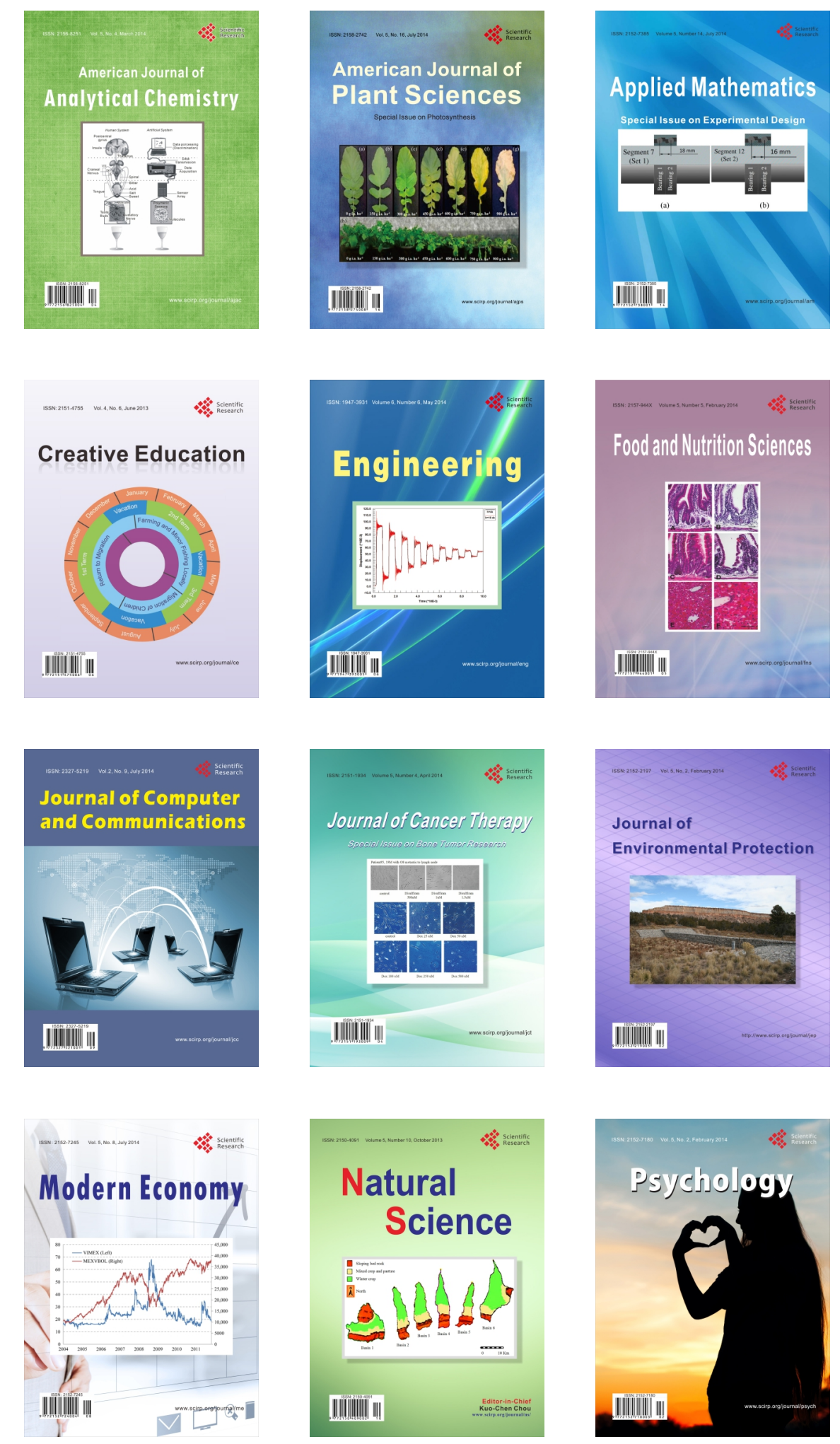